\title{
Effect of general anesthesia on serum $\beta$-amyloid protein and regional cerebral oxygen saturation of elderly patients after subtotal gastrectomy
}

\author{
PENG YU ${ }^{1}$, HUA WANG ${ }^{2}$, LEI MU ${ }^{3}$, XUEMEI DING ${ }^{4}$ and WEI DING ${ }^{5}$ \\ ${ }^{1}$ Department of Anesthesiology, Traditional Chinese Medical Hospital of Rizhao; \\ ${ }^{2}$ Department of Otolaryngology, People's Hospital of Rizhao; Departments of ${ }^{3}$ Neurology, ${ }^{4}$ Surgery and \\ ${ }^{5}$ Neurosurgery, Traditional Chinese Medical Hospital of Rizhao, Rizhao, Shandong 276800, P.R. China
}

Received July 25, 2016; Accepted September 28, 2016

DOI: $10.3892 / \mathrm{etm} .2016 .3814$

\begin{abstract}
The aim of the present study was to investigate the influence of general anesthesia on serum $\beta$-amyloid protein $(\mathrm{A} \beta)$ and regional cerebral oxygen saturation $\left(\mathrm{rSO}_{2}\right)$ of elderly patients after subtotal gastrectomy. From June, 2014 to December, 2015, among 168 patients undergoing subtotal gastrectomy, the Mini-Mental State Examination and Montreal Cognitive Assessment was administered the day prior to surgery and the second and ninth days after the operation. In addition, we administered the tests to 168 healthy adult volunteers (healthy controls) who were treated in our hospital medical center in the same period. Near-infrared spectroscopy technology was used for continuous monitoring of the intraoperative $\mathrm{rSO}_{2}$, and the mean of intraoperative $\mathrm{rSO}_{2}$ was then calculated. Of the 168 patients, 28 developed postoperative cognitive dysfunction (POCD) and the remaining 140 patients were normal (control). The ELISA method was used to test the expression levels of serum $A \beta$ in the three groups and statistical analyses were conducted. Serum $A \beta$ level in the POCD group was significantly higher than that in the control and healthy control groups, and the difference was statistically significant $(\mathrm{P}<0.05)$. The $\mathrm{rSO}_{2}$ level in the patients with POCD was significantly lower than the control group $(\mathrm{P}<0.05)$. The correlation analysis with $\mathrm{A} \beta$ as an independent variable and other factors as dependent variables revealed that the serum $\mathrm{A} \beta$ level negatively correlated with $\mathrm{rSO}_{2}(\mathrm{r}=-1.6749$, $\mathrm{P}<0.05)$. The combined $\mathrm{A} \beta$ and $\mathrm{rSO}_{2}$ may be useful for the diagnosis and prevention of POCD after subtotal gastrectomy under general anesthesia.
\end{abstract}

Correspondence to: Dr Wei Ding, Department of Neurosurgery, Traditional Chinese Medical Hospital of Rizhao, 35 Wanghai Road, Rizhao, Shandong 276800, P.R. China

E-mail: ding_wei_1212@163.com

Key words: postoperative cognitive dysfunction, $\beta$-amyloid protein, subtotal gastrectomy, regional cerebral oxygen saturation

\section{Introduction}

Postoperative cognitive dysfunction (POCD) is a frequent neurological complication after anesthesia. The main clinical manifestations include mental disorder, anxiety, personality changes, and memory impairment; the personality, social skill, and cognitive changes occurring postoperatively are typical manifestations of POCD (1). The incidence rate of POCD among adults older than 75 years of age after general anesthesia was reported to be $40-50 \%$ (1). It was demonstrated that the type of operation, genetics, cholinergic function, Alzheimer's disease molecular neuropathology basis, and anesthesia were correlated with $\beta$-amyloid protein $(A \beta)$ and cholinergic system dysfunction, as well as the roles of different narcotic drugs (2).

Neurological damage and persistent inflammation can cause a significant increase in $A \beta$ and can be used as one of the potential serological markers for diagnosing POCD. The increase in $A \beta$ in the brain may be closely associated with cognitive dysfunction. Furthermore, A $\beta$ in the brain may accumulate and the cerebrospinal fluid concentration may be increased; therefore, plasma $\mathrm{A} \beta$ concentration may reflect the concentration of $A \beta$ in the cerebrospinal fluid (3). This further reflects the degree of POCD, and $\mathrm{A} \beta$ is expected to become one of the serological biomarkers for predicting the occurrence and prognosis of POCD (3). Recent findings showed that, in subtotal gastrectomy patients, the occurrence and development of POCD may be significantly correlated with regional cerebral oxygen saturation $\left(\mathrm{rSO}_{2}\right)$ (4). In elderly patients, the incidence rate of gastric cancer is increasing annually (5). Subtotal gastrectomy is a major operation for gastric cancer, the operative time is long and is further extended by waiting for pathological results and dissecting local lymph nodes. When the long operative time under general anesthesia causes hypoventilation or other respiratory system complications, the gas exchange capacity is impaired and desaturation $\mathrm{rSO}_{2}$ often results, which may be significantly correlated with neurological complications, cognitive function, and prolonged length of stay $(6,7)$. Therefore, it is important to detect early diagnosis indicators and serological markers of POCD so that it can be prevented after subtotal gastrectomy. 
Table I. Comparison of baseline data of included patients (mean \pm SD).

\begin{tabular}{lcccccc}
\hline Groups & $\mathrm{N}$ & Age (years) & BMI $\left(\mathrm{kg} / \mathrm{m}^{2}\right)$ & Operation time $(\mathrm{min})$ & Blood loss $(\mathrm{ml})$ & $\mathrm{MAP}(\mathrm{mmHg})$ \\
\hline POCD & 28 & $64.5 \pm 12.7$ & $21.7 \pm 1.2$ & $192.3 \pm 27.4$ & $178.3 \pm 22.9$ & $78.3 \pm 12.4$ \\
Control & 140 & $66.7 \pm 9.5$ & $20.4 \pm 0.8$ & $196.5 \pm 20.1$ & - & $-7.4 \pm 20.5$ \\
Healthy control & 168 & $65.6 \pm 10.8$ & $20.7 \pm 1.3$ & 0.93 & 0.37 & $76.5 \pm 10.9$ \\
T-value & - & 0.33 & 1.49 & 0.18 & 0.29 & 1.33 \\
P-value & - & 0.47 & 0.12 & 0.28 \\
\hline
\end{tabular}

BMI, body mass index; MAP, mean arterial pressure; POCD, postoperative cognitive dysfunction.

The present study examined the role of $\mathrm{A} \beta$ and $\mathrm{rSO}_{2}$ on POCD of elderly patients undergoing subtotal gastrectomy and its significance and provides theoretical support for the prevention and treatment of POCD based on a review of previous studies.

\section{Materials and methods}

Patients. In total, 168 patients (mean age, $64.5 \pm 10.7$ years) who underwent subtotal gastrectomy under general anesthesia from June 2014 to December 2015 in Traditional Chinese Medical Hospital of Rizhao were included.

Patients diagnosed and confirmed as having stomach cancer or ulcers pathologically by imaging and in line with the subtotal gastrectomy treatment evidence and patients $>60$ years of age, were included in the study.

Exclusion criteria for the study were: i) Immunosuppressant treatments; ii) acute and chronic bacterial and/or viral infection; iii) autoimmune diseases; iv) connective tissue diseases; v) malignancy; vi) liver and kidney dysfunction; vii) chronic muscle disease; viii) peripheral vascular disease, chronic heart failure, thyroid disease, liver and kidney dysfunction, cancer, major trauma in the previous six months and a history of surgical operation; ix) diabetes; x) New York Heart Association class III and IV; xi) in the previous six months, myocardial infarction, percutaneous transluminal coronary angioplasty, coronary artery bypass graft surgery history, and recent application of adrenocortical hormone or other immunomodulatory agents; as well as patients not cooperating with their families, or history of mental illness.

Research methods. Mini-Mental State Examination (MMSE) (8): 1 point for each correct answer, 0 points for wrong or unknown, 9 points for inappropriate answer, 8 points for refusing to answer or not understanding. When calculating the total score, 8 and 9 points were regarded as 0 . The highest score was 30 points. The division of dementia was correlated with educational background; thus, if the elderly adult was illiterate and scored $<17$ points, graduated from primary school and scored $<20$ points, graduated from secondary school or over and scored $<24$ points, the patient was considered to have dementia. Allocation of points was: Normal, 27-30 points; mild, 21-26 points; moderate, 10-20 points; and severe, 0-9 points.

Montreal Cognitive Assessment (MoCA) (9). The testing included visual memory, executive capacity, naming, memory, attention, verbal fluency, abstract thinking, delayed memory, and orientation, for a total of 30 points. One point was added to the test results if the subject had $<12$ years of education, and the education level bias was correlated. Higher scores indicated better cognitive function of the subjects; $\geq 26$ points indicated normal cognition.

Sample collection. After the patients fasted overnight, 3-ml venous blood was extracted from their elbow; $1.2 \mathrm{ml}$ blood was injected into an ordinary plastic tube, and $1.8 \mathrm{ml}$ was injected into an anticoagulant tube containing $0.2-\mathrm{ml} 3.8 \%$ sodium citrate and centrifuged for $10 \mathrm{~min}$ at $1,006.2 \mathrm{x} \mathrm{g}$ within $1 \mathrm{~h}$ after sample collection. The serum or plasma after extraction was placed in a $0.5 \mathrm{ml} \mathrm{EP}$ tube, stored at $-30^{\circ} \mathrm{C}$ and then tested within 1 month.

Expression levels of serum A $\beta$. Enzyme-linked immunosorbent assay (ELISA) was used to test the expression levels of serum A $\beta$. The reagents employed in the present study were purchased from Wuhan Boster Biological Engineering Co., Ltd. (Wuhan, China), and ELISA was performed in full accordance with the operating instructions.

Operative methods. The patients fasted for $8 \mathrm{~h}$ before the operation. The peripheral venous access was opened, and radial artery puncture catheterization was conducted under local anesthesia and then connected to the pressure sensor to monitor arterial pressure. Anesthesia was induced with $0.05 \mathrm{mg} / \mathrm{kg}$ intravenous midazolam, $0.3 \mathrm{mg} / \mathrm{kg}$ etomidate, $10 \mu \mathrm{g} / \mathrm{kg}$ fentanyl, and $0.5 \mathrm{mg} / \mathrm{kg}$ cisatracurium; after endotracheal intubation, mechanical gas exchange was carried out. The abdomen was explored through a central abdominal incision; the greater curvature was separated, and then the lesser curvature (including the right and left gastric arteries). The duodenum and stomach walls were separated and the body of stomach was cut-off for gastrointestinal anastomosis. After anastomosis was complete and the confirmation that there was no residual fistula, the surrounding lymph nodes were further dissected and then the abdomen was closed.

\section{Measurement of $\mathrm{rSO}_{2}$}

Statistical analysis. Measurement data were presented as mean \pm standard deviation (mean \pm SD). SPSS 17.0 software (Chicago, IL, USA) was used for processing. The repeated measures analysis of variance was applied for statistical analysis, the t-test for two independent samples was used for the measurement data among groups, the paired t-test was used for comparison between groups, and the countable data 
Table II. MMSE and MoCA scores of surgical patients in each group.

\begin{tabular}{|c|c|c|c|c|c|c|}
\hline Item & Groups & $\mathrm{N}$ & $\begin{array}{c}\text { One day before } \\
\text { operation }\end{array}$ & $\begin{array}{c}\text { Two days after } \\
\text { operation }\end{array}$ & $\begin{array}{c}\text { Nine days after } \\
\text { operation }\end{array}$ & $\mathrm{P}$-value \\
\hline \multirow[t]{4}{*}{ MMSE } & POCD & 28 & $28.3 \pm 1.6$ & $26.3 \pm 1.4$ & $22.3 \pm 3.2$ & 0.01 \\
\hline & Control & 140 & $29.2 \pm 1.7$ & $29.5 \pm 2.8$ & $28.4 \pm 2.2$ & 0.38 \\
\hline & t-test & - & 0.33 & 8.36 & 10.29 & - \\
\hline & P-value & - & 0.69 & 0.04 & 0.04 & - \\
\hline \multirow[t]{4}{*}{ MoCA } & POCD & 28 & $29.6 \pm 0.4$ & $21.1 \pm 1.8$ & $21.4 \pm 1.3$ & 0.03 \\
\hline & Control & 140 & $28.7 \pm 1.5$ & $26.3 \pm 2.6$ & $28.3 \pm 0.8$ & 0.98 \\
\hline & t-test & - & 0.42 & 20.48 & 20.78 & - \\
\hline & P-value & - & 0.38 & 0.02 & 0.02 & - \\
\hline
\end{tabular}

MMSE, Mini-Mental State Examination; MoCA, Montreal Cognitive Assessment; POCD, postoperative cognitive dysfunction.

Table III. ELISA was used to test the peripheral A $\beta$ levels of patients and healthy controls (ng/ $\mu 1)$.

\begin{tabular}{lcccr}
\hline Groups & $\mathrm{N}$ & $\begin{array}{c}\text { One day before } \\
\text { operation }\end{array}$ & $\begin{array}{c}\text { Two days after } \\
\text { operation }\end{array}$ & $\begin{array}{c}\text { Nine days after } \\
\text { operation }\end{array}$ \\
\hline POCD & 28 & $69.81 \pm 6.33$ & $102.7 \pm 14.5^{\mathrm{a}}$ & $112.4 \pm 14.2^{\mathrm{c}}$ \\
Control & 140 & $64.27 \pm 13.25$ & $75.24 \pm 11.3^{\mathrm{b}}$ & $82.3 \pm 10.1^{\mathrm{d}}$ \\
Healthy control & 168 & $65.37 \pm 10.81$ & $67.3 \pm 2.5$ & 6.002 \\
\end{tabular}

${ }^{a}$ Compared with the control group, $\mathrm{P}<0.05$; ${ }^{\mathrm{b}}$ Compared with the healthy control group, the difference was not statistically significant $(\mathrm{P}>0.05)$; ${ }^{\mathrm{c}}$ Compared with the control group, $\mathrm{P}<0.05$; ${ }^{\mathrm{d}}$ Compared with the healthy control group, the difference was not statistically significant $(\mathrm{P}>0.05)$. ELISA, enzyme-linked immunosorbent assay; $\mathrm{A} \beta, \beta$-amyloid protein; POCD, postoperative cognitive dysfunction.

were tested with $\chi^{2}$ test. $\mathrm{P}<0.05$ was considered to indicate a statistically significant difference.

\section{Results}

Comparison of baseline data of the included patients. We enrolled, recorded, and carried out statistical analysis of the age, weight, body mass index (BMI), and other baseline data of 168 patients with subtotal gastrectomy [28 with POCD (POCD group) and 140 without POCD (control group)] and 168 healthy patients (healthy control group), and there was no statistically significant difference in baseline data among the three groups $(\mathrm{P}>0.05)$ (Table I).

MMSE and MoCA scores of patients in each group. MMSE and MoCA were administered to all the patients on the day before the operation, and on the second and ninth days after the operation. In total, 28 cases demonstrated cognitive dysfunction (POCD group) and 140 patients (control group) did not demonstrate cognitive dysfunction. MMSE and MoCA scores of the patients in the POCD group were statistically significantly decreased compared with the control group $(\mathrm{P}<0.05)$ (Table II).

ELISA was used to test the peripheral A $\beta$ levels of patients and healthy controls. We tested $\mathrm{A} \beta$ levels of the 168 patients with subtotal gastrectomy and 168 healthy controls and found

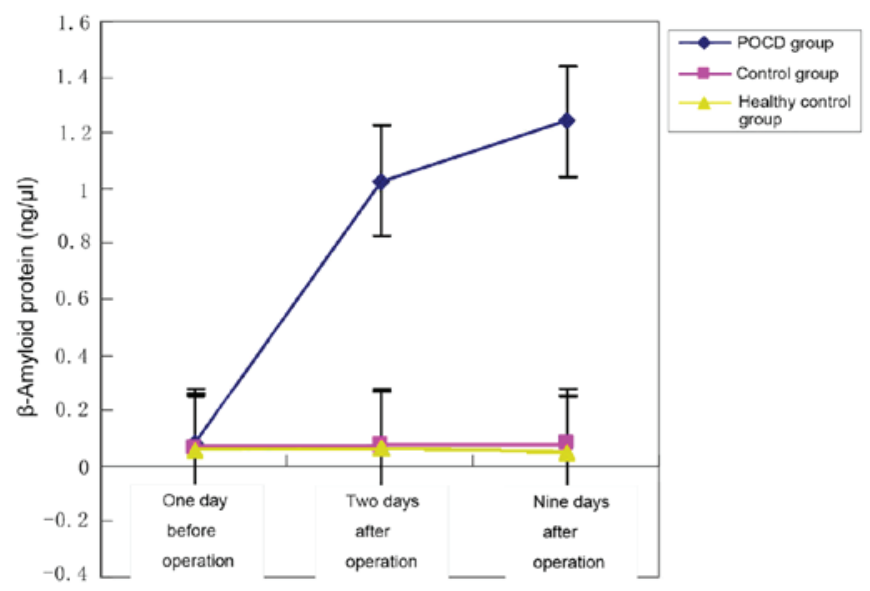

Figure 1. Peripheral $\beta$-amyloid protein (A $\beta$ ) levels of patients and healthy controls. On the second and ninth days after the operation, those in the postoperative cognitive dysfunction (POCD) group were increased significantly compared with the control and healthy control groups. The difference was statistically significant $(\mathrm{P}<0.05)$.

that serum $A \beta$ levels of POCD patients were statistically significantly higher than those in the control and healthy control groups $(\mathrm{P}<0.05)$ (Table III and Fig. 1).

Comparison of $\mathrm{rSO}_{2}$ levels in the two surgical groups. A comparison of the intraoperative mean $\mathrm{rSO}_{2}$ of patients in the 
Table IV. Comparison of $\mathrm{rSO}_{2}$ levels between the two surgical groups.

\begin{tabular}{lcc}
\hline Groups & $\mathrm{N}$ & $\mathrm{rSO}_{2}(\%)$ \\
\hline POCD & 28 & $68.2(60-88)^{\mathrm{a}}$ \\
Control & 140 & $78.3(69-92)^{\mathrm{a}}$ \\
t-test & - & 12.7 \\
P-value & - & 0.03 \\
\hline
\end{tabular}

${ }^{a}$ Values are presented as median (95\% confidence interval). POCD, postoperative cognitive dysfunction; $\mathrm{rSO}_{2}$, regional cerebral oxygen saturation.

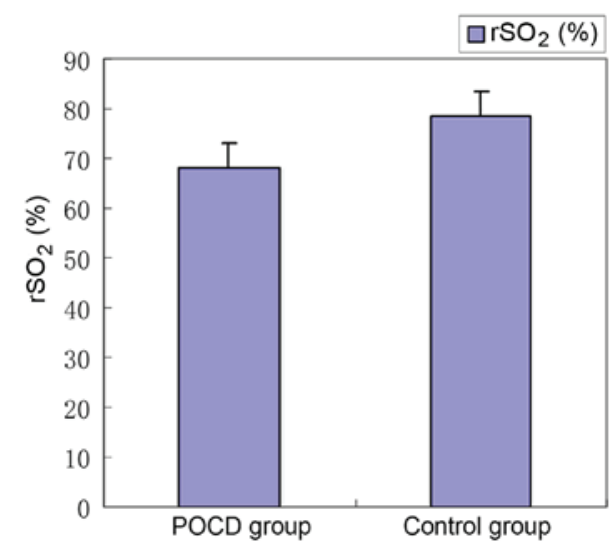

Figure 2. The mean regional cerebral oxygen saturation $\left(\mathrm{rSO}_{2}\right)$ in the post-operative cognitive dysfunction (POCD) group during the operation was significantly lower than that in the control group, and the difference was statistically significant $(\mathrm{P}<0.05)$.

POCD and control groups showed that the mean $\mathrm{rSO}_{2}$ in the sPOCD group during the operation was significantly lower

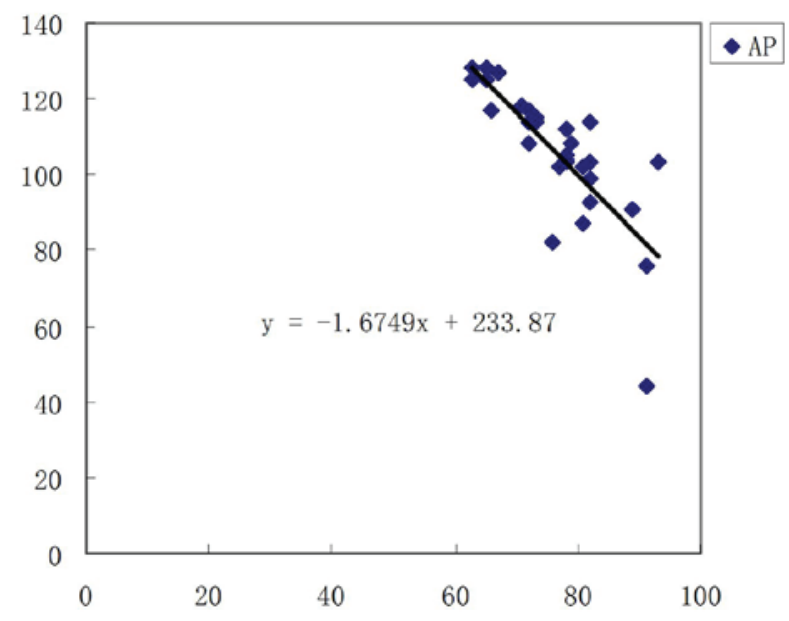

Figure 3. Correlation analysis of $\beta$-amyloid protein $(A \beta)$ protein and Mini-Mental State Examination (MMSE) $y=-1.6749 x+233.87$.

than that in the control group, and the difference was statistically significant $(\mathrm{P}<0.05)$ (Table IV and Fig. 2).

Correlation analysis of $\mathrm{A} \beta$ and $r \mathrm{SO}_{2}$. We carried out the correlation analysis with $\mathrm{A} \beta$ as an independent variable and gender, age, BMI, MMSE and MoCA scores, and $\mathrm{rSO}_{2}$ as dependent variables. The results showed that, $\mathrm{A} \beta$ levels were negatively correlated with $\mathrm{rSO}_{2}$, and the difference was statistically significant $(\mathrm{P}<0.05)($ Table VA and $\mathrm{B}$, and Fig. 3).

Comparison of intraoperative data and postoperative length of stay between POCD group and control group. To study the intraoperative influence of POCD, intraoperative data and postoperative length of stay were compared between the POCD and control patients. Operation time, intraoperative blood loss, and cardiopulmonary bypass time were not significantly different between the two groups $(\mathrm{P}>0.05)$, but postoperative

Table V. Correlation analysis and multiple linear regression analysis.

$A$, Correlation analysis ( $r$ ) of $A \beta$ and clinical testing indicators

\begin{tabular}{lrrrrrr}
\hline Indicators & Gender & Age & BMI & $\mathrm{rSO}_{2}$ & MMSE & MoCA \\
\hline $\mathrm{A} \beta$ & & & & & & \\
$\mathrm{r}$ & 0.02 & 0.35 & 0.29 & -1.6749 & -0.14 & -0.38 \\
P-value & $>0.05$ & $>0.05$ & $>0.05$ & $<0.05$ & $>0.05$ & $>0.05$ \\
\hline
\end{tabular}

$B$, Multiple linear regression analysis of $A \beta$ level influencing factors

$95 \% \mathrm{CI}$

\begin{tabular}{cccccccc}
\cline { 6 - 8 } Variable & $\beta$ & $\mathrm{SE}$ & $\beta^{\prime}$ & t-test & P-value & Upper limit & Lower limit \\
\hline $\mathrm{rSO}_{2}$ & 0.571 & 0.16 & 0.784 & 0.432 & $<0.05$ & 0.29 & 0.87 \\
\hline
\end{tabular}

A $\beta, \beta$-amyloid protein; BMI, body mass index, CI, confidence interval; MMSE, Mini-Mental State Examination; MoCA, Montreal Cognitive Assessment; $\mathrm{rSO}_{2}$, regional cerebral oxygen saturation. 
Table VI. Comparison of intraoperative data and postoperative length of stay between POCD and control groups.

\begin{tabular}{lcccc}
\hline Groups & No. of cases & Operation time $(\mathrm{min})$ & Amount of bleeding $(\mathrm{ml})$ & Postoperative length of stay (days) \\
\hline POCD & 28 & $187.4 \pm 21.4$ & $287.4 \pm 68.7$ & $22.4 \pm 2.8$ \\
Control & 140 & $190.3 \pm 25.3$ & $298.6 \pm 48.2$ & $14.3 \pm 1.7$ \\
T-value & - & 1.28 & 0.59 & 18.5 \\
P-value & - & 0.21 & 0.48 & 0.012 \\
\hline
\end{tabular}

POCD, postoperative cognitive dysfunction.

length of stay was significantly prolonged in the POCD group $(\mathrm{P}<0.05)($ Table VI).

\section{Discussion}

At present, the pathogenesis of POCD remains unclear. However, the dysfunction involving the central nervous system, endocrine system, and immune system may contribute to the pathogenesis of POCD (10). Furthermore, A $\beta$ is produced by many cells and circulates in the blood, cerebrospinal fluid, and brain interstitial fluid, and the studies show that $\mathrm{A} \beta$ is neurotoxic, and $A \beta 1-42$ is especially toxic $(11,12)$.

$\mathrm{A} \beta$ deposition is not only correlated with neuronal degenerative disease, but can also activate a series of pathological changes in the central nervous system, including activation of astrocytes and microglia, breakdown of the blood-cerebrospinal fluid barrier, and microcirculation disturbance. In a previous report, neuronal degeneration was often seen in the region of the senile plaques in the brains of patients with Alzheimer's disease, which may cause death (13). In the current study, we found that expression levels of serum $A \beta$ were statistically significantly higher in patients with POCD than controls and healthy controls $(\mathrm{P}<0.05)$. We believe that this may be correlated with longer operative times and potential brain damage caused by hypoventilation. Therefore, we confirmed this hypothesis by further monitoring the intraoperative $\mathrm{rSO}_{2}$. We found that, in the patients with postoperative POCD, the $\mathrm{rSO}_{2}$ level was significantly higher than those of patients without $(\mathrm{P}<0.05)$.

$\mathrm{rSO}_{2}$ monitoring is continuous and non-invasive. The oxygen saturation of cerebral hemoglobin can be intraoperatively monitored in real time by monitoring the mixing transmission intensity of the oxyhemoglobin and reduced hemoglobin of head and neck. The normal value of $\mathrm{rSO}_{2}$ is $55-75 \%$. The ratio of cerebral arterial/venous flow is 15:85 (14). Therefore, $\mathrm{rSO}_{2}$ mainly shows cerebral venous oxygen saturation and reflects the balance between supply and demand of oxygen $(13,15)$. As the most sensitive system to hypoxia stimulation in the body, the central nervous system has a high oxygen demand. The cerebral blood flow accounts for $15 \%$ of total cardiac output under a rest state, and oxygen consumption accounts for $23 \%$ of total oxygen consumption. Under a normal physiological status, $A \beta$ that can be detected in the blood and cerebrospinal fluid is usually at lower levels, because the body has a strong scavenging activity for $A \beta$ (16). If peripheral $A \beta$ antibody (immunoglobulin $\mathrm{G}$ ) permeates into the brain, it can bond with $\mathrm{A} \beta$, forming a kind of immune complex precipitation and activating the microglia, thereby cleaning up the deposition of $\mathrm{A} \beta$.
However, intraoperative hypopnea results in microglial physiological dysfunction and often reduces the scavenging activity for $A \beta$, thereby resulting in $A \beta$ deposition in local neurons. This results in neuron deficiency and cutin hyperplasia, and induces neuronal apoptosis in a dose-dependent manner (7,17-20). This is in accordance with our study outcomes. We have discovered that the peripheral blood $\mathrm{A} \beta$ level has an apparent negative correlation with $\mathrm{rSO}_{2}$. However the internal relations of this correlation need to be validated via animal experiment and cell experiment. According to the above results, we believe that reasonable control of time of subtotal gastrectomy and ventilatory capacity during the operation is clinically significant for reducing the incidence of postoperative $\operatorname{POCD}(21,22)$.

In conclusion, the expression level of $A \beta$ in serum of the patients with POCD was significantly increased, and the combined $\mathrm{A} \beta$ and $\mathrm{rSO}_{2}$ may be indicators for diagnosis and prevention of POCD after subtotal gastrectomy under general anesthesia.

\section{References}

1. Vatter H, Konczalla $\mathbf{J}$ and Seifert V: Endothelin related pathophysiology in cerebral vasospasm: what happens to the cerebral vessels? Acta Neurochir Suppl 110: 177-180, 2011.

2. Peng L, Xu L and Ouyang W: Role of peripheral inflammatory markers in postoperative cognitive dysfunction (POCD): a meta-analysis. PLoS One 8: e79624, 2013.

3. Hu Y, Shi S, Liu X, Hu Z, Huang W, Wang D, Xu J, Cheng B, Fang $X$ and Shu Q: Effects of heart bypass surgery on plasma $A \beta 40$ and $A \beta 42$ levels in infants and young children. Medicine (Baltimore) 95: e2684, 2016.

4. Saito $\mathrm{S}$ and Ishii H: Early detection of iliac artery rupture by sudden steep reduction of regional saturation of oxygen at the ipsilateral foot during transcatheter aortic valve implantation - a case report. Masui 65: 184-188, 2016 (In Chinese).

5. Venerito M, Vasapolli R and Malfertheiner P: Prevention, early diagnosis and therapy of gastric cancer. MMW Fortschr Med 158: 39-43, 2016 (In German).

6. Tuna AT, Akkoyun I, Darcin S and Palabiyik O: Effects of carbon dioxide insufflation on regional cerebral oxygenation during laparoscopic surgery in children: a prospective study. Rev Bras Anestesiol 66: 249-253, 2016 (In Portuguese)

7. Li XM, Li F, Liu ZK and Shao MT: Investigation of one-lung ventilation postoperative cognitive dysfunction and regional cerebral oxygen saturation relations. J Zhejiang Univ Sci B 16: 1042-1048, 2015.

8. Ong HL, Subramaniam M, Abdin E, Wang P, Vaingankar JA, Lee SP, Shafie S, Seow E and Chong SA: Performance of Mini-Mental State Examination (MMSE) in long-stay patients with schizophrenia or schizoaffective disorders in a psychiatric institute. Psychiatry Res 241: 256-262, 2016.

9. Marceau EM, Lunn J, Berry J, Kelly PJ and Solowij N: The Montreal Cognitive Assessment (MoCA) is sensitive to head injury and cognitive impairment in a residential alcohol and other drug therapeutic community. J Subst Abuse Treat 66: 30-36, 2016. 
10. Nesaratnam A, Nesaratnam $\mathrm{N}$ and Agius $\mathrm{M}$ : Cognitive impairment following use of anaesthetic agents: a review of the literature, and implications for future practice. Psychiatr Danub 26 (Suppl 1): 53-55, 2014.

11. Xu Z, Dong Y, Wang H, Culley DJ, Marcantonio ER, Crosby G, Tanzi RE, Zhang Y and Xie Z: Age-dependent postoperative cognitive impairment and Alzheimer-related neuropathology in mice. Sci Rep 4: 3766, 2014.

12. Vlisides P and Xie Z: Neurotoxicity of general anesthetics: an update. Curr Pharm Des 18: 6232-6240, 2012.

13. Erdem AF, Kayabasoglu G, Tas Tuna A, Palabiyik O, Tomak Y and Beyaz SG: Effect of controlled hypotension on regional cerebral oxygen saturation during rhinoplasty: a prospective study. J Clin Monit Comput 30: 655-660, 2016.

14. Ide K and Secher NH: Cerebral blood flow and metabolism during exercise. Prog Neurobiol 61: 397-414, 2000.

15. Picton P, Dering A, Alexander A, Neff M, Miller BS, Shanks A, Housey M and Mashour GA: Influence of ventilation strategies and anesthetic techniques on regional cerebral oximetry in the beach chair position: a prospective interventional study with a randomized comparison of two anesthetics. Anesthesiology 123: 765-774, 2015

16. Barten DM, Guss VL, Corsa JA, Loo A, Hansel SB, Zheng M, Munoz B, Srinivasan K, Wang B, Robertson BJ, et al: Dynamics of $\beta$-amyloid reductions in brain, cerebrospinal fluid, and plasma of $\beta$-amyloid precursor protein transgenic mice treated with a $\gamma$-secretase inhibitor. J Pharmacol Exp Ther 312: 635-643, 2005.
17. Hametner C, Stanarcevic P, Stampfl S, Rohde S, Veltkamp R and Bösel J: Noninvasive cerebral oximetry during endovascular therapy for acute ischemic stroke: an observational study. J Cereb Blood Flow Metab 35: 1722-1728, 2015.

18. Mousa WF, Mowafi HA, Al-Metwalli RR, Al-Ghamdi AA and Al-Gameel HZ: Preoperative mannitol infusion improves perioperative cerebral oxygen saturation and enhances postoperative recovery after laparoscopic cholecystectomy. Saudi Med J 36: 1199-1204, 2015

19. Xie Z and Tanzi RE: Alzheimer's disease and post-operative cognitive dysfunction. Exp Gerontol 41: 346-359, 2006.

20. Jo YY, Kim JY, Park CK, Chang YJ and Kwak HJ: The effect of ventilation strategy on arterial and cerebral oxygenation during laparoscopic bariatric surgery. Obes Surg 26: 339-344, 2016.

21. Ding L, Zhang H, Mi W, Sun L, Zhang X, Ma X and Li H: Effects of carbon dioxide pneumoperitoneum and steep Trendelenburg positioning on cerebral blood backflow during robotic radical prostatectomy. Nan Fang Yi Ke Da Xue Xue Bao 35: 712-715, 2015 (In Chinese)

22. Lin R, Zhang F, Xue Q and Yu B: Accuracy of regional cerebral oxygen saturation in predicting postoperative cognitive dysfunction after total hip arthroplasty: regional cerebral oxygen saturation predicts POCD. J Arthroplasty 28: 494-497, 2013 